\title{
KAJIAN KONSEP ARSITEKTUR BAMBU PADA BANGUNAN SEKOLAH ALAM PANYADEN THAILAND
}

\author{
Achmad Ryan Abimanyu ${ }^{1}$, Anggana Fitri Satwikasari ${ }^{2}$ \\ ${ }_{1}$ Program Studi Arsitektur, Fakultas Teknik, Universitas Muhammadiyah Jakarta \\ 2 Program Studi Arsitektur, Fakultas Teknik, Universitas Muhammadiyah Jakarta \\ Email: 2017460002@ftumj.ac.id
}

\begin{abstract}
ABSTRAK
Sekolah alam merupakan sebuah sistem pendidikan yang sedang berkembang, sekolah alam mempunyai sistem pendidikan yang mengenalkan anak dengan alam sekitarnya. Sebagai pendukung dari sekolah alam bangunan dengan konsep berkelanjutan merupakan salah satu cara. Salah satu material berkelanjutan adalah bambu, bambu merupakan material yang sudah ada sejak lama di dunia. Bambu merupakan material yang mempunyai banyak potensi dalam bidang arsitektur, bambu dapat digunakan sebagai struktur utama bangunan dan mempunyai estektika bentuk tersendiri dalam bidang arsitektur. Bambu merupakan material yang sangat baik dalam mendukung pembelajaran di sekolah alam karena merupakan rancangan yang tepat dan baik.
\end{abstract}

Kata Kunci: Sekolah Alam, Bangunan Berkelanjutan, Bambu, Arsitektur Bambu Article history: Received 2021-03-11; Revised 2021-04-12; Accepted 2021-05-11

\section{PENDAHULUAN}

Sekolah alam merupakan sebuah konsep pendidikan yang awalnya di gagas oleh Lendo Novo berdasarkan keprihatinanya akan biasa Pendidikan yang semakin tidak terjangkau oleh masyarakat. Namun seiring dengan berkembangnya sekolah alam menjadi sebuah alternatif sebagai pengembangan struktur emosi, mentalitas dan sikap setiap anak agar menjadi individu yang lebih baik ke depannya. (Hamdani,2015). Dengan begitu sebagai sebuah sekolah yang mendukung program siswa/I untuk mengenali kondisi alam dengan baik diperlukanya sebuah knsep berkelanjutan dengan menggunakan material kontruksi berkelanjutan.

Bangunan berkelanjutan adalah suatu proses pembangunan yang mengoptimalkan manfaat dari sumber daya alam dan manusia. Konstruksi berkelanjutan menekankan peningkatan efisiensi dalam penggunaan air, energi, dan material bangunan mulai dari desain, pembangunan hingga pemeliharaan bangunan tersebut. Terdapat banyak material dalam sebauh bangunan berkelanjutan salah satunya adalah bambu. Bambu merupakan salah satu material konstruksi bangunan sejak dulu, bambu merupakan salah satu material yang memiliki banyak potensi. Bambu mempunyai nilai ekologis yang baik sehingga merupakan salah satu material berkelanjutan.

Setiap bangunan sekolah alam dengan konsep bangunan berkelanjutan yang menggunakan konstruksi bambu akan di tinjau dari bentuk arsitektural serta bentuk strukturnya yang mengkaji sistem struktur, konfigurasi dan bentuk dari setiap penempatakn elemen 
struktural dan sistem struktrural dalam menyalurkan beban. Bambu merupakan salah satu material yang mampu mendukung berdirinya sebuah bangunan sekolah alam, karena bambu merupakan material alam yang kokoh dan kuat.

Bambu yang sudah ada sejak jaman dahulu juga sudah menjadi bagian hidup masyarakat Indonesia, terutama masyarakat agraris di pedesaan, bahkan bagi orang desa di Indonesia, bambu merupakan primadona untuk pelaksanaan kegiatan yang berkaitan dengan pembangunan rumah. Pemanfaatan bambu untuk bangunan rumah, adalah untuk tiang-tiang penyangga, dinding, konstruksi atap dan konstruksi lantai (Sukawi, 2008 melalui Amir Mukmin Rachim,2011). Maka dari itu bambu merupakan salah satu material struktur bangunan yang dapat menunjukan estetika dengan kekuatan yang sangat baik.

Tujuan dari penelitian ini adalah menjadi sebuah data analisis yang komparatif. Bangunan ini merupakan bangunan berkelanjutan. Hal ini dapat di manfaatkan oleh perancang untuk mengembangkan wawasan sistem struktur yang mungkin dapat di terapkan pada bentuk serupa. Selain itu penelitian ini memberikan refrensi lain sebagai sebuah desain bangunan.

\section{TINJAUAN PUSTAKA}

Sekolah alam merupakan salah satu jawaban atas perbaikan sistem pendidikan yang seragam dan bertujuan untuk mengembangkan potensi anak sesuai dengan kemampuannya. (Suhendi dkk,2012). Sekolah alam berarti harus mempunyai sebuah konsep bangunan berkelanjutan agar mendukung sistem belajar dan mengajar para siswa/i. Menurut (Natsir Abduh, 2017) bangunan yang berkelanjutan mengacu pada struktur dalam proses yang bertanggung jawab terhadap lingkungan dan sumber daya yang efisien pada tahapan pelaksanaan bangunan. Perencanaan dimulai dari penentuan tapak, desain konstruksi, operasional, pemeliharaan, maupun renovasi dan pembongkaran akan tetapi yang lebih penting didahului dengan uji analisis mengenai dampak lingkungan. Salah satu material berkelanjutan adalah bambu.

Pada perkembangan bambu mengalami eksplorasi material yang di Indonesia sudah cukup banyak dan beragam, baik dari sisi bentuk maupun penyelesaian konstruksi hingga detail sambungan bambunya. Kesamaan prinsip yang muncul dapat terjadi karena beberapa bangunan memang dirancang oleh arsitek yang sama(Ardhiana Muhsin,2018). Maka dari itu penggunaan bambu sangatlah efektif bagi kemajuan prinsip bangunan berkelanjut sebagai salah satu aspek pengurangan efek Global Warming.

\section{METODE PENELITIAN}

Penelitian ini menggunakan metode deskritif kualitatif, setiap aspek aspek dalam penelitian ini akan di deskripsikan dan di identifikasikan berdasarkan analisis pada landasan teori yang diangkat sebagai panduan, pendekatan yang digunakan dalam penelitian ini yaitu pendekatan 
deduktif. Penelitian menggunakan pendekatan kualitatif diharapkan mampu menghasilkan uraian yang mendalam tentang ucapan, tulisan dan organisasi tertentu dalam suatu setting konteks tertentu yang dikaji dari sudut pandang yang utuh, komprehensif dan holistic. Penggunaan metode ini berdasarkan tujuan yang akan dicapa, yakni mendapatkan gambaran mengenai konsep arsitektur bambu pada studi kasus sekolah alam Panyaden Thailand.

\section{PEMBAHASAN DAN HASIL PENELITIAN}

Sekolah alam Panyaden Thailand ini mempunyai konsep arsitektur bambu yang digunakan pada struktur bangunan dan struktur tambahan pada bangunan. Hal tersebut digunakan sebagai pendukung dari konsep sekolah alam. Pembasan berisi penggunaan bambu yang digunakan pada studi kasus.

\section{a. Analisis Jenis Bambu Yang Digunakan}

Konsep pada bangunan sekolah alam Panyaden Thailand yaitu bangunan hijau dengan menggunakan material bambu yang digunakan sebagai struktur kolom, struktur atap dan lainnya. Bambu yang digunakan adalah bambu petung dengan nama latin dendrocalamus asper bambu ini banyak tumbuh di Thailnad dan merupakan bambu lokal . bambu tersebut mempunyai ciri yaitu ruas dengan panjang antara $40-50 \mathrm{~cm}$ dan berdiameter $12-18 \mathrm{~cm}$ dengan tebal buluh dapat mencapai $3 \mathrm{~cm}$. Gambar dibawah ini merupakan ciri - ciri bambu petung:

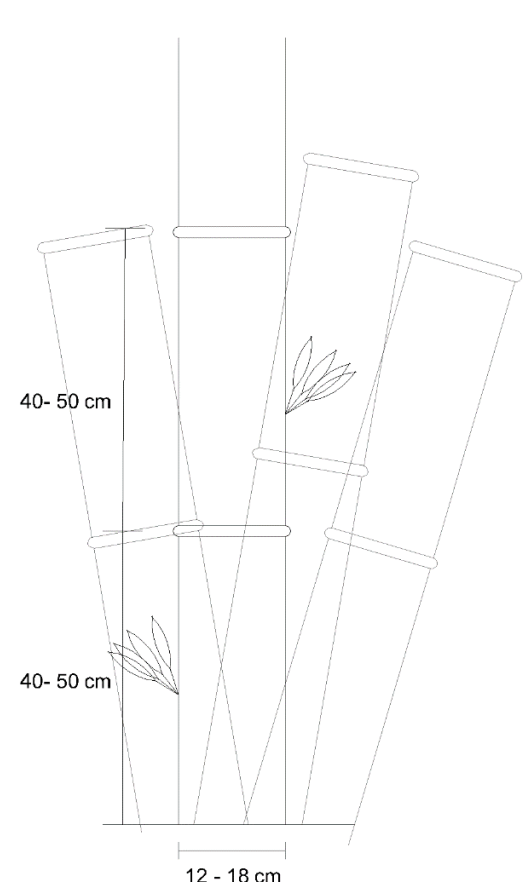

Gambar.1 Dimensi Bambu Petung 
Pada bangunan sekolah alam Panyaden Thailand menggunakan bambu petung sebagai struktur bangunan karena di nilai sangat baik dalam bidang arsitekturnya. Bambu petung mempunyai kekuatan dan estetika yang baik dalam penggunaanya.

\section{b. Sifat - Sifat Bahan Bambu}

Bambu yang digunakan adalah bambu petung dengan nama latin dendrocolamus asper mempunyai warna hijau hingga kuning pada bagian batang dan buluhnya. Bambu petung mempunyai batang 5 - 11 cabang pada satu rumpun. Bulu - bulunya di kelilingi oleh akar udara yang kokoh, pada bagian bawah buluh muda tertutup bulu seperti beludru. Buluh mempunyai warn atua hijau dan hijau keungguan atau hijau keputih putihan dan bertotol putih karena tertutup lumut.

Bambu yang digunakan sebagai struktur utama pada bangunan di sekolah Panyaden Thailand adalah bambu petung karena bambu tersebut mempunyai gaya tarik dan gaya tekan yang baik sebagai struktur sebuah bangunan. Tabel di bawah ini akan menjelaskan mengenai kuat tarik dan tekan bambu petung:

Tabel. 1 Kuat Tarik dan Tekan Bambu Pentung

\begin{tabular}{ccc} 
Bagian Ruas & Kuar Tarik $\mathbf{( k g / \mathbf { c m } ^ { 2 } )}$ & Kuat Tekan $\mathbf{( k g / \mathbf { c m } ^ { 2 } )}$ \\
\hline Pangkal & 2.278 & 2.769 \\
\hline Tengah & 1.770 & 4.089 \\
\hline Ujung & 2.080 & 5.479 \\
\hline
\end{tabular}

Sumber: Heinz Frick, 2020

\section{c. Metode Dan Teknik Penggabungan Bahan Bambu Yang Berbeda}

Bangunan sekolah alam Panyaden Thailand menggunakan beberapa material sambungan yang berbeda. Metode sambungan yang digunakan pada pemasangan bambu dengan bambu lainya menggunakan metode baut dan sabut kelapa. Pada gambar dibawah ini merupakan sambungan yang digunakan pada studi kasus sekolah alam Panyaden Thailand:

- Baut

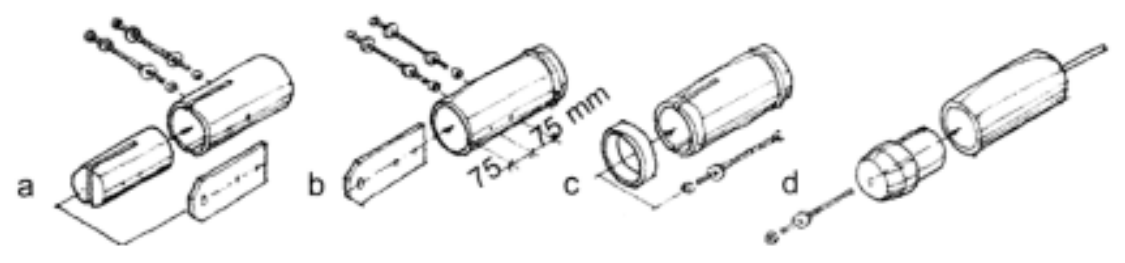

Gambar.2 Contoh Penggabungan Bambu Dengan Baut Sumber: Heinz Frick, 2020 
- Serabut Kelapa

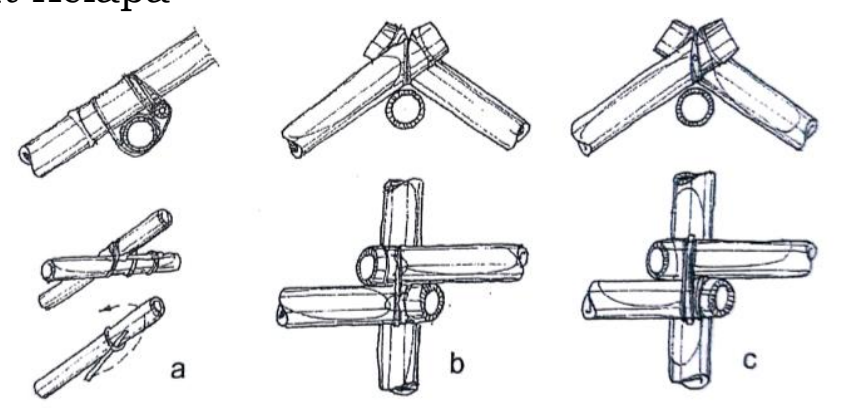

Gambar.3 Contoh Penggabungan Bambu Dengan Baut

Sumber : Heinz Frick, 2020

Pada sekolah alam Panyaden Thailand digunakan 2 jenis penggabungan yang terbagi menjadi 3 bagian yaitu atas, tengah dan bawah. Bagian atas yang merupakan atap bangunan, tengah yang merupakan tubuh bangunan dan bawah merupakan kaki bangunan. Terdapat 3 bangunan dengan penggabungan yang berbeda, berikut gambar analisis:

A. Classroom Pavilion

Bangunan ini mempunyai sambungan bambu yaitu baut. Baut digunakan pada bagian struktur atap dan pada bagian tengah baut digunakan sebagai struktur kolom penyambung kolom bambu dengan balok maupun dengan struktur atap.

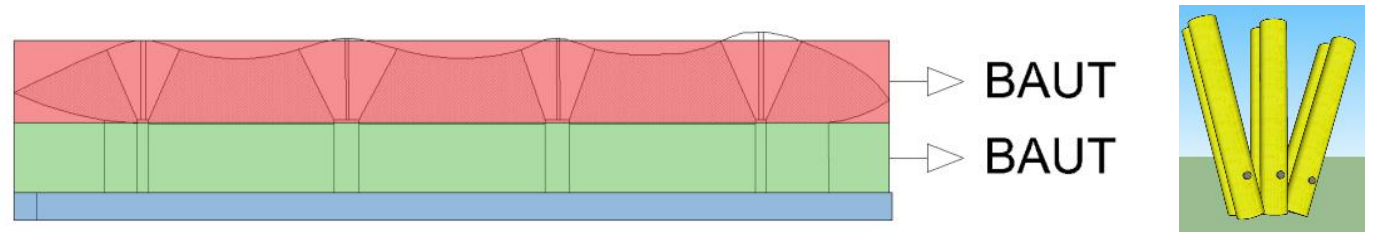

\section{Gambar.4 Ilustrasi Penggabungan Baut Pada Classroom Pavilion}

B. Sala Palvilion

Bangunan ini mempunyai sambungan bambu yaitu baut. Baut digunakan pada bagian struktur atap dan pada bagian tengah baut digunakan sebagai struktur kolom penyambung kolom bambu dengan balok maupun dengan struktur atap.
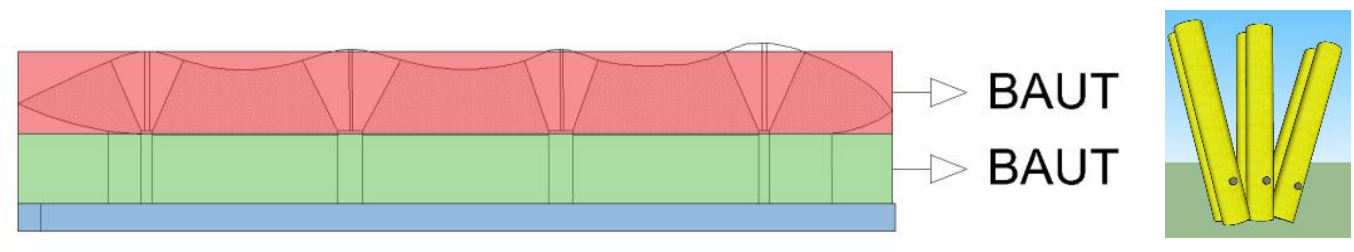

Gambar.5 Ilustrasi Penggabungan Baut Pada Sala Pavilion 


\section{Sport Hall}

Bangunan ini mempunyai sambngan pada bagian atas atau atap adalah baut sebagai penguatnya. Penggabungan ini menguatkan setiap unsurnya seperti pada reng dengan balok atap atau dengan kolom. Pada bagian tengah digunakan 2 jenis sambungan yaitu baut dan serabut kelapa. Serabut digunakan sebagai penggabungan bambu dengan bambu lainya menjadi satu dan dikuatkan dengan baut sebagai material tambahan agar menjadi lebih kuat.

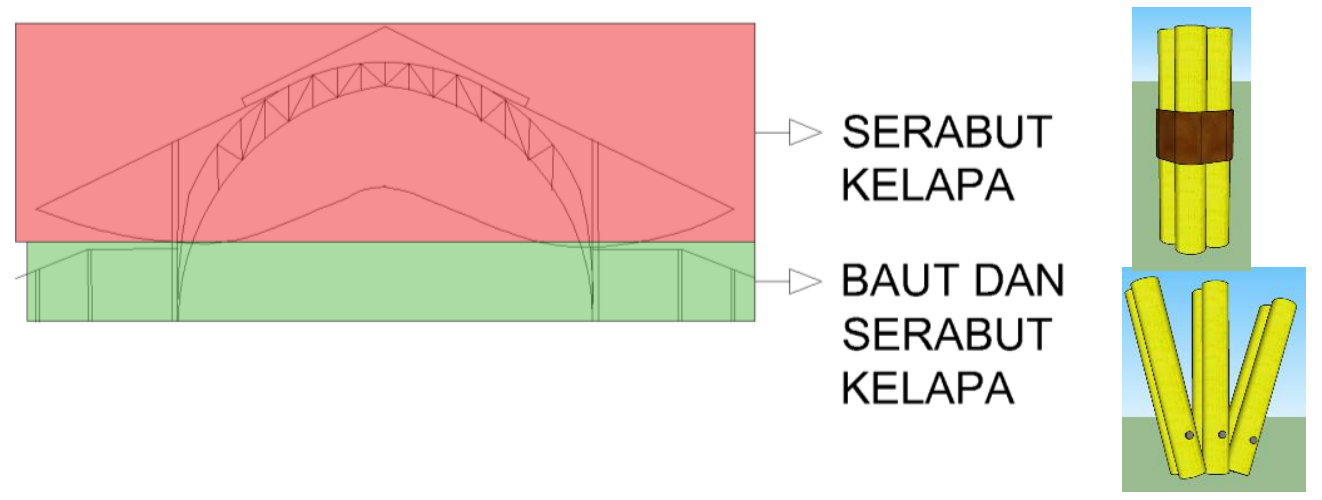

Gambar.6 Ilustrasi Penggabungan Baut dan Serabut Kelapada Pada Sport Hall

Pada sekolah alam Panyaden Thailand mempunyai 2 sambungan bambu dengan bambu maupun material alinya. Beberapa contoh penggabungan tersebut berada pada sporthall dan ruang pavilion. Untuk mempermudah dapat di lihat pada tabel dibawah ini :

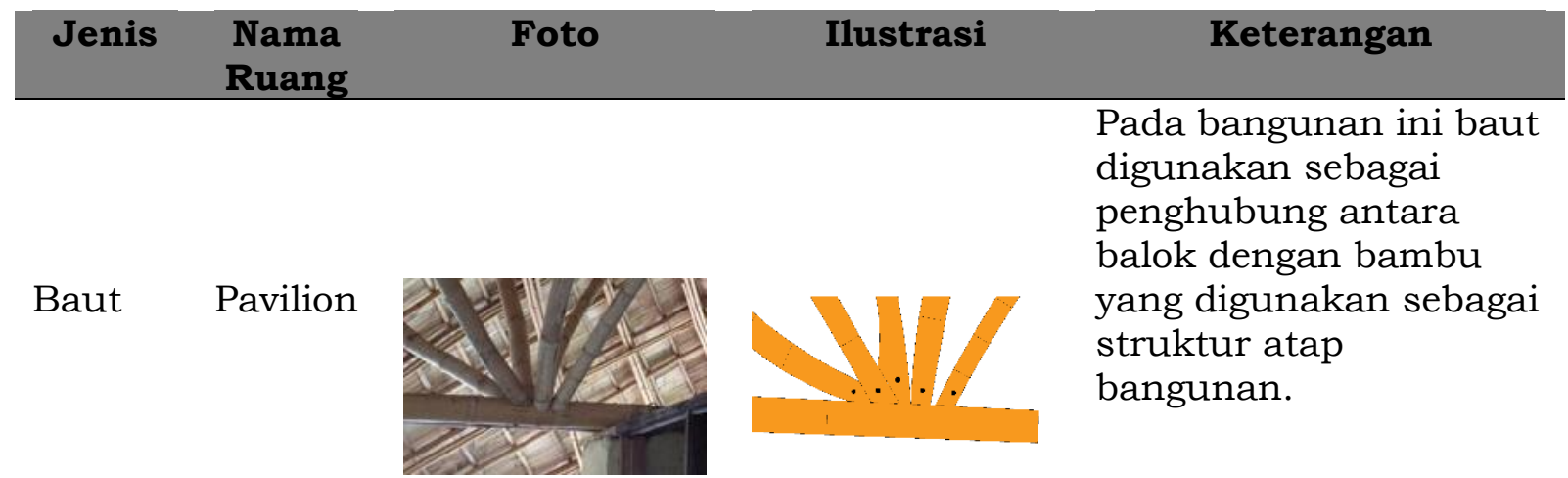




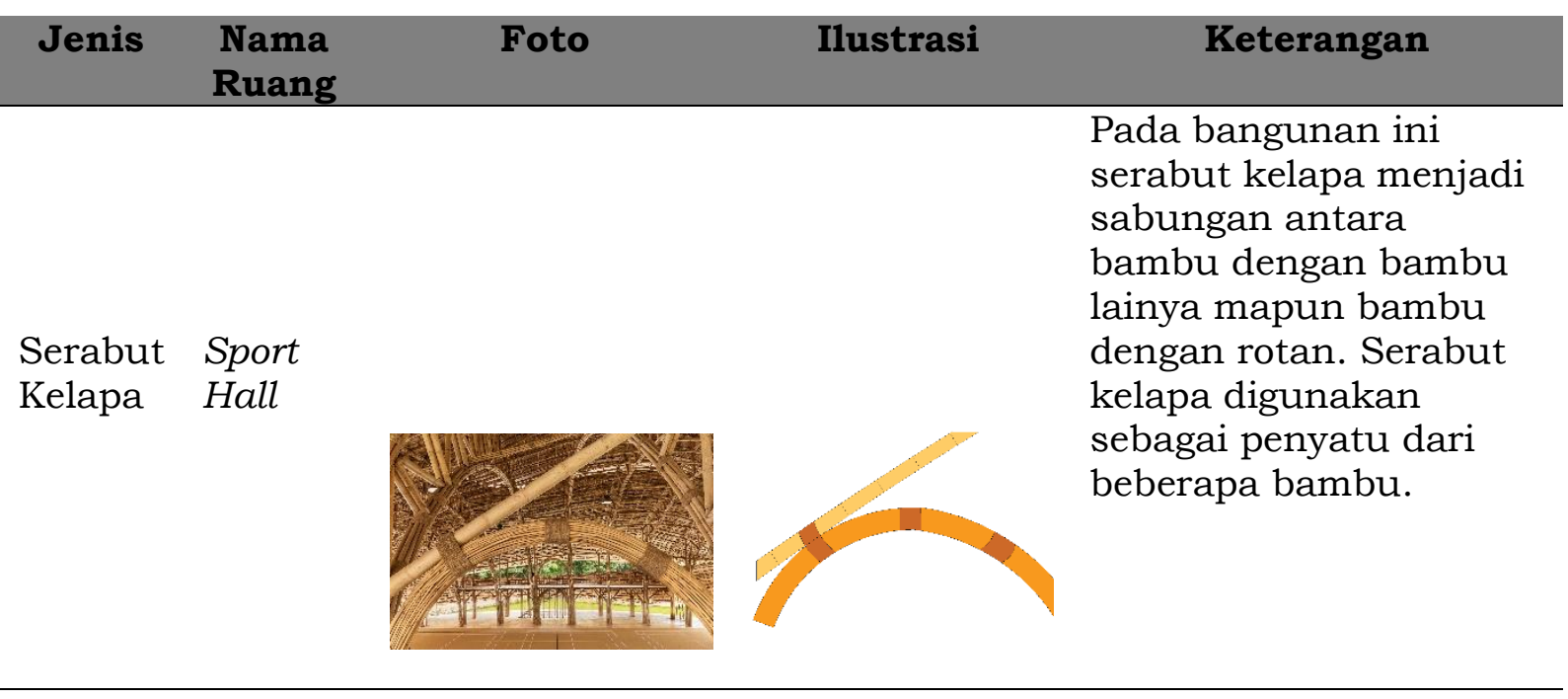

\section{Statistika Visual}

Bangunan sekolah alam Panyaden Thailand merupakan bangunan dengan konsep arsitektur bambu. Bangunan ini terbuat dari material berkelanjutan seperti bambu, beton dan tanah liat. Bangunan yang ada pada sekolah tersebut mempunyai statistika visual yang berebda tergantung dari bentuk ketinggian ruang dan beban yang ada di dalam bangunan tesebut. Di bawah ini merupakan analisis statistika visual bentuk dari setiap bangunan :

- Classroom Pavilion

Bangunan ini merupakan bangunan yang digunakan sebagai tempat belajar mengajar. Bangunan ini berlantai 1 dengan atap nipah dan di sambungkan ke bambu dengan kolom bangunan. Penyaluran beban pada bangunan ini adalah rangka batang. Pada sambungan penyaluran bebanya adalah aksial transversal sehingga beban akan disalurkan melalui kolom- kolom maupun tembok vertikal lalu ke pondasi.

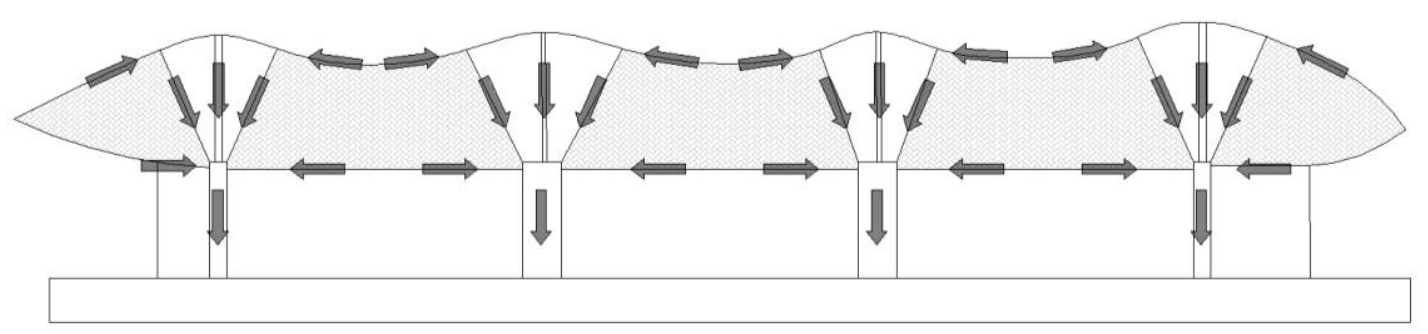

Gambar.7 Sketsa Statistika Samping Classroom Pavilion 


\section{- Sala Pavilion}

Bangunan ini merupakan bangunan yang digunakan sebagai tempat berkumpul maupun belajar. Bangunan ini mempunyai atap nipah sekaligus tembok yang menutupi bangunan. Beban yang terjadi pada atap disalurkan langsung melalui kolom yang menyatu dengan atap tersebut. Sehingga beban yang terjadi lagsung turun menuju pondasi,

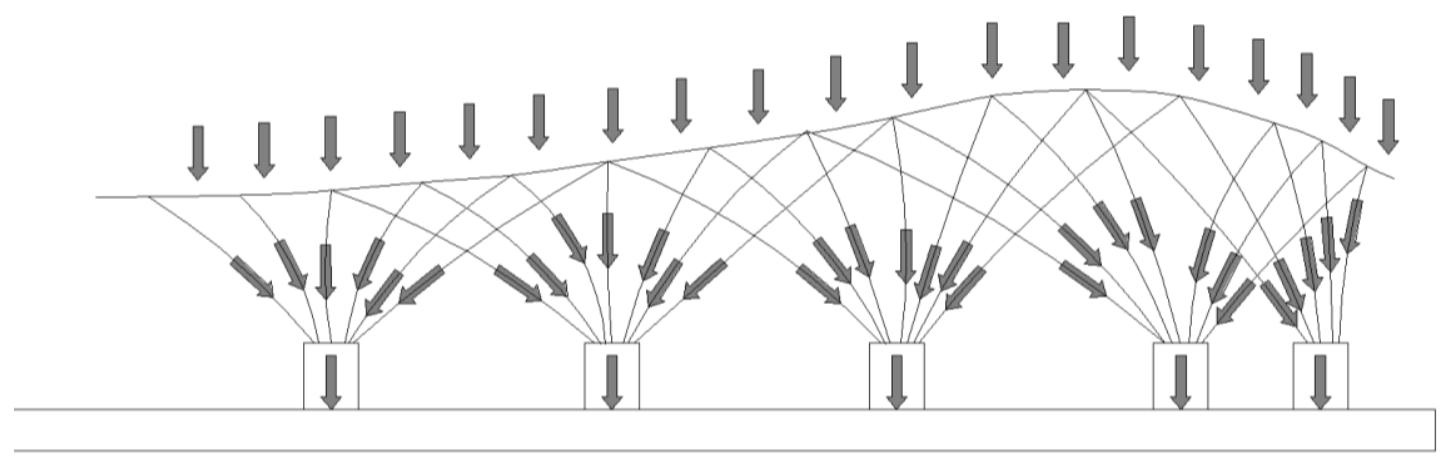

\section{Gambar.8 Sketsa Statistika Samping Sala Pavilion}

\section{- Sport Hall}

Bangunan ini merupakan bangunan bentang lebar yang digunakan sebagai tempat olahraga atau aula yang digunakan untuk berbagai acara. Bangunan ini merupakan bangunan bentang lebar dengan struktur bambu pada setiap material bangunanya. Sistem struktur ini adalah busur, penyaluran bebanya adalah aksial tekan. Bambu tidak disusun tegak lurus sehingga adanya gaya batang tarik diantara kedua kolom. Penyaluran bebanya dari atap menuju ke pondasi.

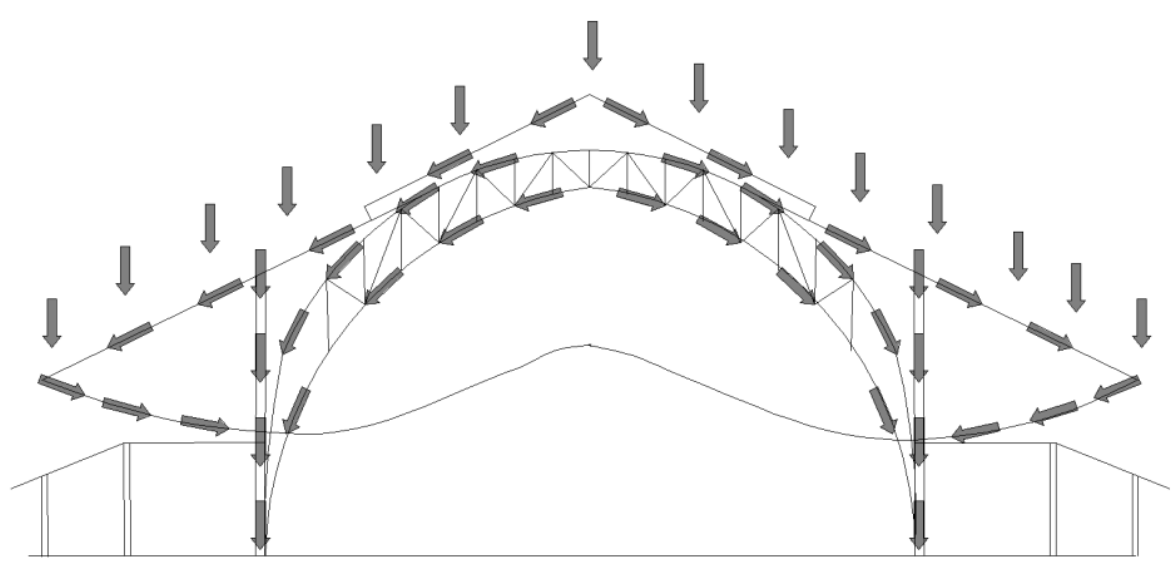

Gambar.9 Sketsa Statistika Depan Sport Hall

\section{SIMPULAN}

Bambu merupakan material yang banyak digunakan di dunia maupun di Indonesia. Bambu merupakan material alami yang banyak tumbuh di seluruh dunia. Bambu dapat digunakan sebagai material dalam bidang 
arsitektur karena mempunyai nilai- nilai lebih dalam penggunaanya. Bambu petung merupakan bambu yang digunakan dalam bidang arsitektur, bambu petung mempunyai gaya tarik dan gaya tekan yang baik dan mampu dijadikan struktur utama dalam sebuah bangunan. Terdapat berbagai sambungan pada bambu dengan bambu lainya maupun bambu dengan material lainya. Pada studi kasus sekolah alam Panyaden Thailand terdapat 2 jenis sambungan bambu yaitu baut dan serabut kelapa. Pada sekolah alam Panyaden Thailand terdapat statistika visual yang disalurkan melalui struktur kolom maupun tembok bangunan. Bambu merupakan material yang cocok untuk penggunaan sekolah alam karena selain mendukung konsep alam, bambu juga merupakan material berkelanjutan.

\section{DAFTAR RUJUKAN}

Natsir Abduh. 2017. Teknologi Green Pada Bangunan Berkelanjutan M. Seminar Ilmiah Nasional Teknik Sipil Universitas Bosowa SINALTSUB I. hal 1

Ahmad Hamdani. 2015. Sekolah alam: Alternatif Pendidikan Ramah Anak. HARKAT: Media Komunikasi Islam Tentang Gender dan Anak, 11. Hal 3.

Amir Mukmin Rachim. 2011. Penggunaan Potensi Bahan Lokal Pada Karya Arsitektur Nusantara Studi Kasus: Penggunaan Bahan Bambu Pada Arsitektur Nusantara Samawa Nusa Tenggara Barat. Simposium Nasional RAPI X FT UMS. Hal 2.

Ardhiana Muhsin. 2018. Eksplorasi Material Bambu pada Bangunan Publik. Seminar nasional itenas 2018. Hal 1.

Heinz Frick. 2004. Ilmu Konstruksi Bangunan Bambu Pengantar Konstruksi Bambu. Edisi 8. Yogyakarta. 